\section{$\underset{\substack{\text { hommes } \\ \text { \& migrations }}}{ }$}

\section{Hommes \& migrations}

Revue française de référence sur les dynamiques

migratoires

1307 | 2014

L'Afrique qualifiée dans la mondialisation

\title{
Globalisation et mobilité pour études
}

\section{Hamidou Dia}

\section{(2) OpenEdition \\ Journals}

\section{Édition électronique}

URL : http://journals.openedition.org/hommesmigrations/2870

DOI : 10.4000/hommesmigrations.2870

ISSN : 2262-3353

\section{Éditeur}

Musée national de l'histoire de l'immigration

\section{Édition imprimée}

Date de publication : 1 juillet 2014

Pagination : 6-7

ISBN : 978-2-919040-28-5

ISSN : $1142-852 X$

\section{Référence électronique}

Hamidou Dia, « Globalisation et mobilité pour études », Hommes \& migrations [En ligne], 1307 | 2014 mis en ligne le 01 juillet 2017, consulté le 01 mai 2019. URL : http://journals.openedition.org/ hommesmigrations/2870; DOI : 10.4000/hommesmigrations.2870 


\section{GLOBALISATION ET MOBILITÉ POUR ÉTUDES}

Dossier proposé par HAMIDOU DIA, chargé de recherche à l'Institut de recherche pour le développement (IRD).

Les mobilités pour études constituent une des modalités les moins étudiées des migrations internationales, en dépit de l'ancienneté du phénomène et de l'intérêt qu'il suscite de plus en plus auprès des spécialistes, des États et de certains organismes internationaux. Les statistiques disponibles pointent pourtant le caractère significatif du fait : en 2009, selon l'Unesco, près de 3 millions d'étudiants sont inscrits dans des établissements d'enseignement supérieur en dehors de leur pays d'origine, le plus souvent dans les pays du Nord, notamment ceux de l'Organisation de coopération et de développement économiques (OCDE). A priori, on peut penser que ces mouvements concernent davantage les ressortissants des pays riches où se trouvent les universités et les écoles qui caracolent en tête des classements mondiaux. Néanmoins, d'après les mêmes sources, les étudiants originaires de l'Afrique subsaharienne sont les plus mobiles au monde.

Si l'internationalisation de la formation des étudiants n'est pas nouvelle, elle prend une autre tournure avec la globalisation économique qui intègre toutes les parties du monde, certes à des degrés différents. Elle connaît surtout des transformations rapides et intenses qui requièrent, pour les appréhender, la mobilisation de toutes les sciences sociales. Ce dossier souhaite interroger les dynamiques nouvelles des mobilités pour études à partir du cas des étudiants originaires de l'Afrique subsaharienne. D'abord, en raison de la place qu'ils occupent dans ces mouvements et qui fait d'eux, par conséquent, les principaux acteurs ; ensuite, parce que s'est développée à partir du continent africain une tradition de migrations étudiantes qui offre matière à une mise en perspective à partir, notamment, des indépendances. Aussi les schémas classiques d'orientation des étudiants sontils remis en question. Les étudiants optent pour des établissements d'enseignement supérieur de pays sans passé politique et/ou linguistique commun. À l'intérieur même du continent émergent de nouveaux pôles universitaires attractifs à la faveur d'une série de facteurs qu'il convient d'identifier : Johannesburg, Dar-Es-Salam, Accra, Kampala, Cotonou, Dakar, Rabat, Casablanca ou Tunis sont de grandes villes qui accueillent des candidats des pays voisins. Enfin, les performances économiques récentes de certains pays africains, quoique fragiles, font apparaître des classes moyennes éduquées développant des stratégies de formation de plus en plus sophistiquées à l'intérieur comme 
Amphithéâtre Léon Robert,

université Félix-Houphouët-Boigny (Abidjan), mars 2010 (c) CAmille Millerand

en dehors du continent. Des étudiants issus des classes populaires intègrent, dans des conditions difficiles, ces mouvements internationaux.

Le dossier ambitionne de mettre à jour les nouvelles dynamiques des mobilités étudiantes à travers quatre axes. En premier lieu, on peut interroger les politiques publiques nationales et internationales qui structurent ces migrations pour études. Précisément, il est question ici des offres de formation et des dispositifs d'incitation mis en place à la fois par des organismes internationaux privés ou publics, les pays de départ et les pays d'accueil. Ensuite, il s'agit d'étudier la relation entre mobilité pour études et mobilité sociale à travers la question de l'intégration dans un marché du travail national ou international. En effet, ce qui caractérise désormais les étudiants originaires d'Afrique noire, c'est une grande hétérogénéité en raison des différenciations produites par des appartenances de classe. Dece fait, sont étudiés ici les filières et les établissements de formation choisis, la valeur des diplômes obtenus à létranger et la capacité à les monnayer au retour dans le pays d'origine ou à l'étranger en fonction des milieux sociaux et des réseaux susceptibles d'être mobilisés. On cherchera à comprendre comment se donnent à lire la reproduction, le déclassement ou l'ascension sociale à travers les migrations étudiantes.

Le dossier offre aussi l'opportunité de reposer, sur la base de nouveaux travaux empiriques, la question du lien des étudiants ayant fini leur cursus, notamment ceux qui intègrent le marché du travail du territoire d'études, avec leur pays d'origine. Doit-on parler comme certains de "fuite des cerveaux" ou comme d'autres de "circulation des compétences"? Si circulation des compétences il y a, comment s'opère-t-elle ? Qui en sont les acteurs individuels et institutionnels et/ou organisationnels ? Quels sont les impacts ? Comment se positionnent les pays d'origine et d'accueil par rapport à un tel état de fait? Les débats se posent-ils dans les mêmes termes partout, en Afrique comme dans le reste du monde, notamment dans les pays de l'OCDE ? Enfin, il est important d'acter les transformations des mobilités subsahariennes à l'intérieur du continent, comme dans le reste du monde, en faisant le portrait de grands pôles de la présence estudiantine internationale africaine. Quelles sont les grandes villes qui accueillent des étudiants étrangers africains ? S'il est possible de les identifier, quelles sont les dynamiques qui entourent cette présence? Quelle est l'histoire de ces pôles? Quel rôle jouent-ils dans la formation des élites africaines? 